Case Report

\title{
Cutaneous Plasmablastic Lymphoma in an Immunocompetent Patient with Long-Term Pyrimethamine Use for Essential Thrombocythemia: A Case Report and Literature Review
}

\author{
Ing Soo Tiong, ${ }^{1}$ Magreet Strauss, ${ }^{2}$ Michael B. Y. Lau, ${ }^{2}$ and Shingirai Chiruka ${ }^{1,2}$ \\ ${ }^{1}$ Southern Blood and Cancer Service, Dunedin Hospital, Private Bag 1921, Dunedin 9054, New Zealand \\ ${ }^{2}$ Division of Haematology, Southern Community Laboratories, Dunedin 9016, New Zealand \\ Correspondence should be addressed to Shingirai Chiruka; shingi.chiruka@southerndhb.govt.nz
}

Received 4 December 2012; Accepted 10 January 2013

Academic Editors: E. Bissé, K. Khair, S. Langabeer, Y. Matsukawa, A. Ohsaka, Y. Shiozawa, and T. Sonoki

Copyright (C) 2013 Ing Soo Tiong et al. This is an open access article distributed under the Creative Commons Attribution License, which permits unrestricted use, distribution, and reproduction in any medium, provided the original work is properly cited.

We report a case of Epstein-Barr-virus-(EBV-) positive primary cutaneous plasmablastic lymphoma in a human-immunodeficiency-virus-(HIV-) negative, immunocompetent 62-year-old female patient. We postulate that her lymphoma development is due to the longstanding use of pyrimethamine for essential thrombocythemia. This has never been described in the literature.

\section{Case Report}

A 62-year-old woman was initially diagnosed with essential thrombocythemia (ET) on the basis of bone marrow aspirate and trephine at age 36 (November 1986), which was later proven to be Janus kinase 2 V617F mutation (JAK2) positive. She was started on hydroxyurea in July 1987 due to platelet counts of $>1000 \times 10^{9} / \mathrm{L}$ and recurrent transient neurological symptoms. This was subsequently changed to pyrimethamine in September 1994 due to concerns about the leukemogenic risk of hydroxyurea. She otherwise maintained good health other than a history of osteoporotic T8 compression fracture.

In February 2012, she presented to our service with a 3month history of fevers, weight loss, and lethargy. She also noted a general discomfort and brownish discoloration in her left leg during the same period (Figure 1(a)), which was managed by the vascular surgeons as venous insufficiency. Her peripheral blood film showed leukoerythroblastic changes. Bone marrow aspirate and trephine biopsy showed features consistent with ET including megakaryocytic hyperplasia and megakaryocytes of large complex nuclei. There was no evidence of myelofibrotic or acute leukemic transformation.

Shortly after the previously mentioned, she was admitted under the respiratory team with an atypical pneumonia. During the inpatient stay, she noticed increasing nodular appearance on her leg. On physical examination, she had multiple nodular lesions extending from mid shin to ankle (Figure 1(b)). There was no ulceration, bleeding, or discharge from the lesions. There was no palpable lymphadenopathy or hepatosplenomegaly. A punch biopsy of the lesion was subsequently performed.

The biopsy showed a diffuse dermal infiltrate of large pleomorphic cells, some with plasmacytic differentiation (cells with rounded nuclei, coarser chromatin, and smaller nucleoli) and others with the appearance of immunoblasts (cells with enlarged nuclei, vesicular chromatin, and a single prominent nucleolus) (Figure 2(a)). Immunohistochemistry showed these to be negative for CD20 and stain positive for CD138, Bcl-2, CD45, and CD79a (weak), with a high Ki-67 proliferation index approaching 50\% (Figures 2(b) to 2(e)). Pan-cytokeratins and melanoma markers (S-100, Melan-A) were negative, as was the staining for other lymphoid markers (CD2, CD56, CD30, Bcl-6, and TdT). Staining for EpsteinBarr virus (EBV) by in situ hybridization (EBV EBERISH) showed positive nuclear staining (Figure 2(f)). This was consistent with the diagnosis of plasmablastic lymphoma.

Staging investigation including a magnetic resonance imaging (MRI) of the left leg confirmed the subcutaneous lesions and adjacent myositis of tibialis anterior without any bony involvement (Figures 3(a) and 3(b)). MRI of 


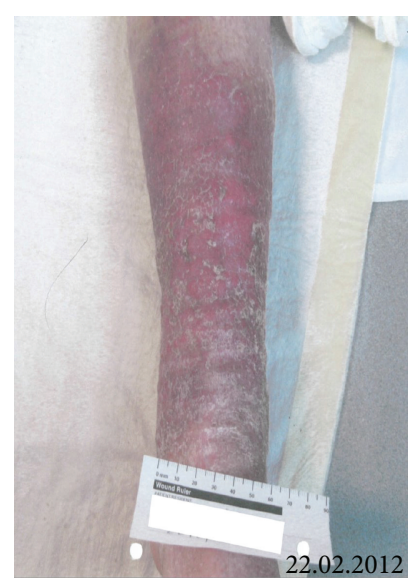

(a)

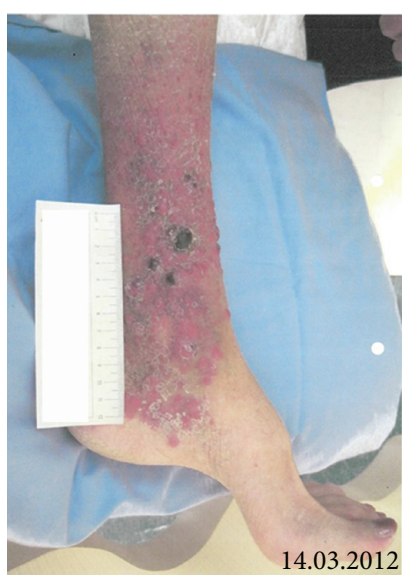

(b)
FIGURE 1: Skin.

the spine showed the T8 compression fracture with no other suspicious osseous lesions (Figures 4(a) and 4(b)). Whole body computed tomography (CT) scan revealed no other site of disease other than a mild splenomegaly at $16.2 \mathrm{~cm}$.

Other relevant investigations included hemoglobin $106 \mathrm{~g} / \mathrm{L}(115-155 \mathrm{~g} / \mathrm{L})$, platelet $123 \times 10^{9} / \mathrm{L}\left(150-430 \times 10^{9} / \mathrm{L}\right)$, neutrophils $8.7 \times 10^{9} / \mathrm{L}\left(1.9-7.5 \times 10^{9} / \mathrm{L}\right)$, LDH $1151 \mathrm{IU} / \mathrm{L}(85-$ 225 units/L), $\beta_{2}$-microglobulin $6.51 \mathrm{mg} / \mathrm{L}(1.00-3.50 \mathrm{mg} / \mathrm{L})$, IgA kappa monoclonal protein $7 \mathrm{~g} / \mathrm{L}$, and IgG kappa monoclonal protein $<1 \mathrm{~g} / \mathrm{L}$. Patient was serologically negative for hepatitis $\mathrm{B}$, hepatitis $\mathrm{C}$, and human immunodeficiency (HIV) viruses. There was serological evidence of past EBV and cytomegalovirus exposure.

This confirmed a diagnosis of stage $1 \mathrm{~B}$ primary cutaneous plasmablastic lymphoma in a HIV-negative host without evidence or history of immunosuppression. The pyrimethamine was stopped, and combination chemotherapy with cyclophosphamide, doxorubicin, vincristine, and prednisone (CHOP) was started every three weeks. After the first cycle of the CHOP her platelet count started rising as the pyrimethamine had been stopped. Rather than introducing another antiproliferative agent, she was changed to $\mathrm{CHOP}$ every 14 days with pegylated growth factor support. This effectively controlled the platelet counts. She completed 6 cycles of chemotherapy which was then followed by a course of consolidation radiotherapy with 3600 cGy over 18 fractions. This resulted in a near resolution of the skin nodules and the myositis on the repeat of MRI scan (Figures 3(c) and $3(d))$.

However, patient developed increasing back pain in August 2012. MRI spine showed multilevel compression fractures at T6, T8, L1, L3, and L5 as well as abnormal marrow signal at T11 and T12 suspicious for lymphomatous infiltration (Figures 4(c) and 4(d)). Rather than having vertebral biopsies, due to frailty, she was treated with a single fraction ( $600 \mathrm{cGy}$ ) of radiotherapy. A CT scan of chest, abdomen, and pelvis at this time did not demonstrate any lymphadenopathy.
At the time of writing, she is still alive, 10 months after the diagnosis of PBL, and has complete resolution of the leg lesion. Her back pain is controlled with moderate amount of opiates. Platelet counts remain controlled without an antiproliferative agent.

\section{Discussion}

Plasmablastic lymphoma (PBL) is a relatively new clinical entity described as a separate entity from diffuse large Bcell lymphoma [1]. It was initially described in HIV-infected individuals, involving the oral cavity [2]. However, cases of PBL involving extraoral sites are becoming increasingly recognized, particularly in HIV-negative patients [3-5].

Immunophenotyping is an important adjunct in differentiating $\mathrm{PBL}$ from other neoplasms. PBL expresses a plasma cell phenotype with positive CD138, CD38, Vs38c, and IRF4/MUM1 and are negative or only weakly positive for CD45 and CD20 (and PAX5). CD79a is positive in approximately $50-85 \%$ of the cases. $\mathrm{Ki} 67$ index is usually very high. EBV EBER is positive in up to $75 \%$ of the cases [1].

Important morphological differentials in this case would include diffuse large B-cell lymphoma (DLBCL), not otherwise specified; primary cutaneous diffuse large B-cell lymphoma, leg type; plasma cell myeloma or plasmacytoma; myeloid sarcoma; and metastatic melanoma. In this case, both forms of DLBCL are excluded due to the negative CD20. Plasma cell neoplasms are typically monomorphic in appearance and usually express CD56 and lack of EBV expression. MPO and S-100 negativity rule out myeloid sarcoma and metastatic melanoma, respectively.

To date, 25 cases of PBL presenting in the skin have been reported [6-31], with male predominance $(n=17$ or $68 \%$ ), and over half were HIV positive ( $n=14$ or $56 \%$ ). Excluding the HIV-positive hosts, the gender distribution becomes much move even, with 6 males and 6 females. Interestingly, half of the cases had presentation involving the lower limb (12/24 or $50 \%)$. EBV was implicated in $80 \%$ $(16 / 20)$ of the cases. At diagnosis, 10 cases had localized cutaneous PBL without systemic disease, whereas 8 cases had systemic involvement at diagnosis. No information could be ascertained about systemic involvement in 7 other patients.

Most of the previously mentioned patients were immunosuppressed with HIV infection $(n=14)$, posttransplantation $(n=8)$, or autoimmune disorder $(n=1)$. Two patients, however, were immunocompetent hosts without any history of acquired or iatrogenic immunosuppression. These two patients were an 80-year-old male [7] and an 86-year-old female [26], respectively. To our knowledge, our patient would represent the third reported case of cutaneous PBL in an immunocompetent host.

Liu et al. [32] recently reported a series of 10 patients with PBL who were negative for HIV and had no other known immunodeficiency conditions, other than advanced age (median age $=68$ years). Of note, none of these cases presented with skin lesions. The term plasmablastic lymphoma of the elderly (PBL-E) has been coined to account for the immunosenescence state found in these patients. 


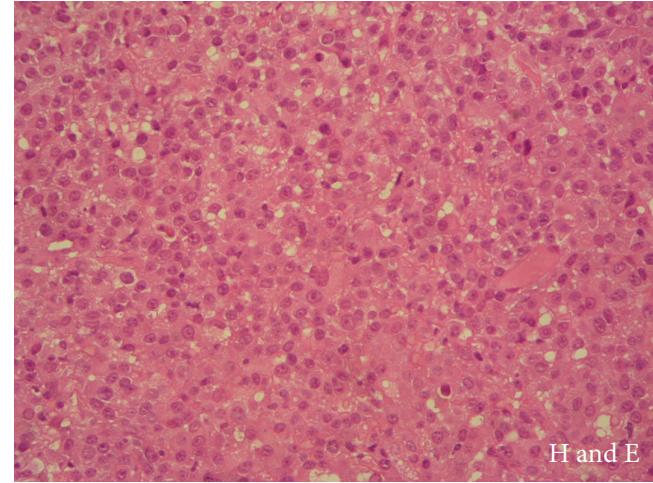

(a)

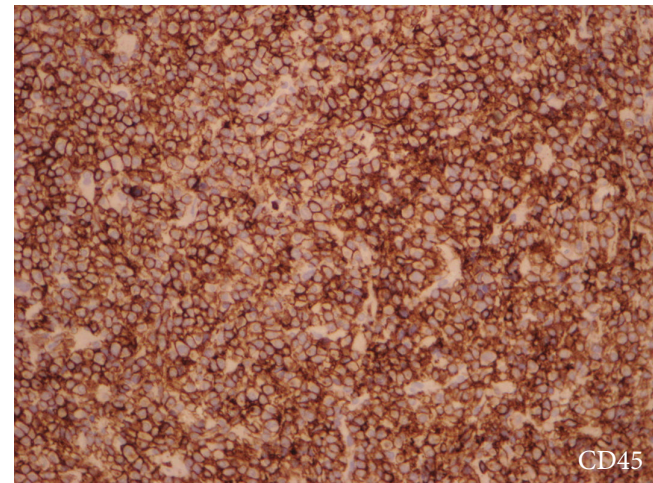

(c)

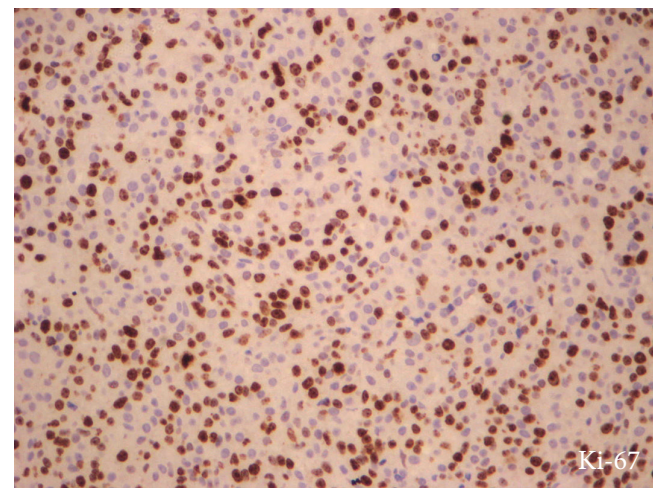

(e)

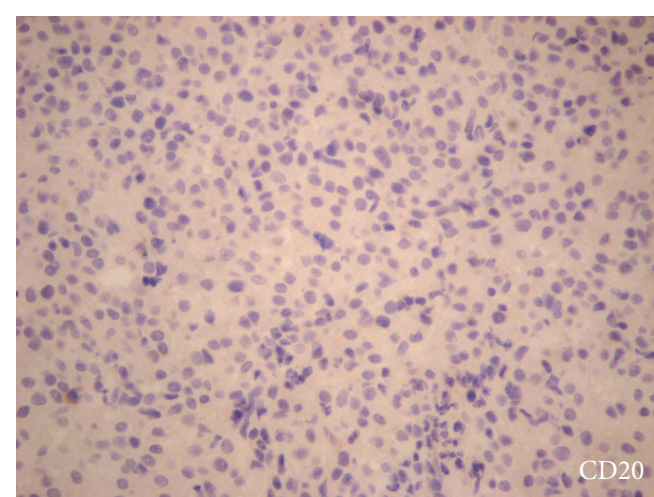

(b)

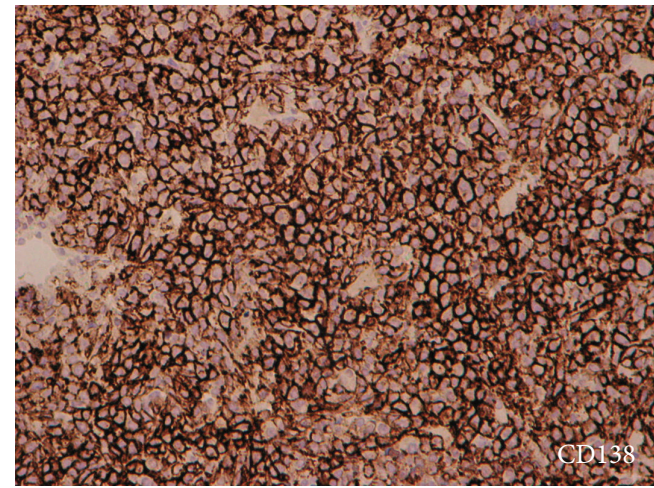

(d)

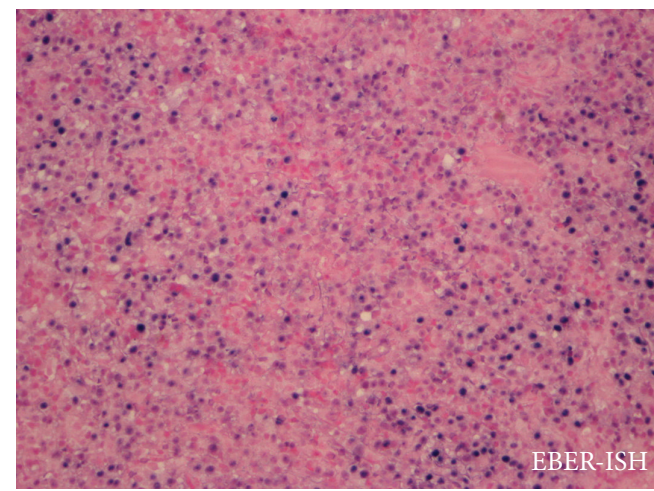

(f)

Figure 2: Punch biopsy of the left leg.

This bears several similarities to age-related EBV-associated B-cell lymphoproliferative disorder (AR-EBV LPD), which was newly listed in the 2008 World Health Organization classification of lymphoid neoplasms.

One unique feature of this case is the long-standing use of pyrimethamine, a dihydrofolate reductase inhibitor. It is rarely used for myeloproliferative disorder in this era due to other more effective treatments. Its main use currently is for prevention and treatment of malaria and toxoplasmosis. We suspect that it might be involved in the immune dysregulation and thus the pathogenesis of her PBL. Animal studies demonstrated that pyrimethamine could enhance antibody responses to sheep red blood cell, augment delayed-type hypersensitivity response $[33,34]$, inhibit signal transducer and activator of transcription 3 (STAT3) pathway [35], and induce apoptosis of several cell lines [36-38]. Little is known about the effect of long-term pyrimethamine use on immune status. We could only identify a single case of non-Hodgkin's lymphoma developing in the gut in a patient while being on pyrimethamine [39]. It can rarely cause a pseudolymphoma drug reaction [40]. We could not identify any reported cases of PBL in association with myeloproliferative disorder. 


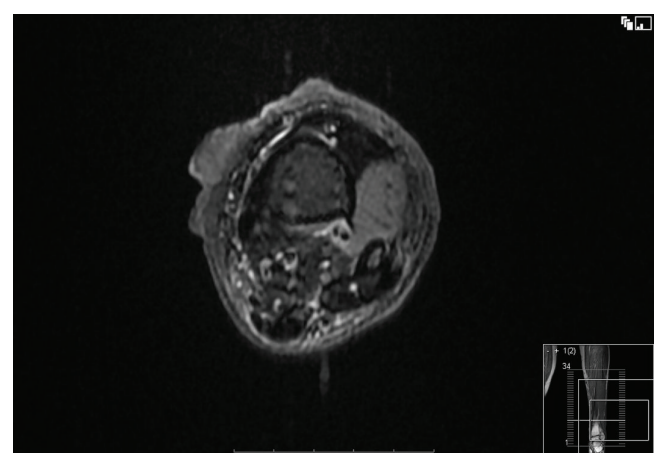

(a)

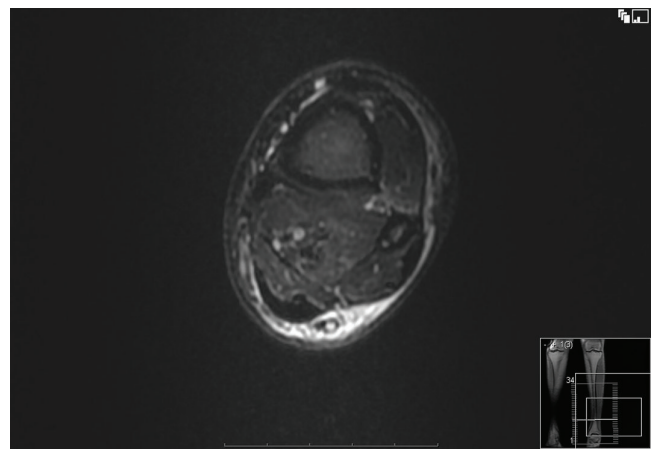

(c)

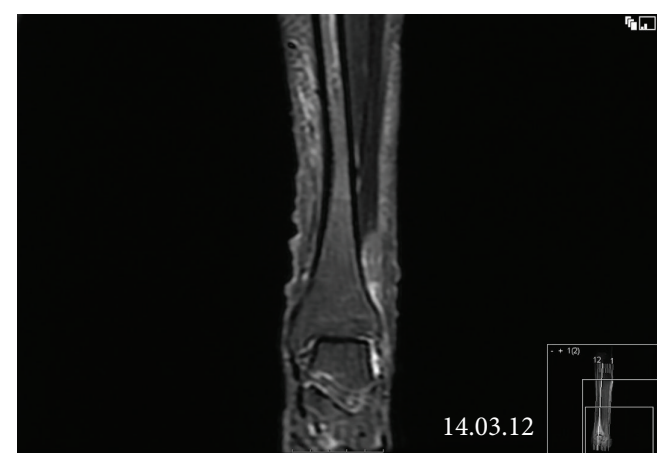

(b)

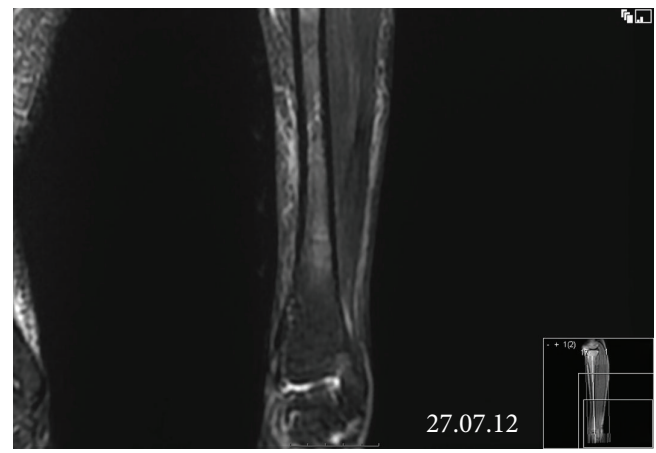

(d)

FIGURE 3: MRI of the left leg. Subcutaneous nodules and myositis of tibialis anterior are shown on T2 fat-saturated axial view (a) and short T1 inversion recovery (STIR) coronal view (b). After treatment, the changes are resolved (c, d).

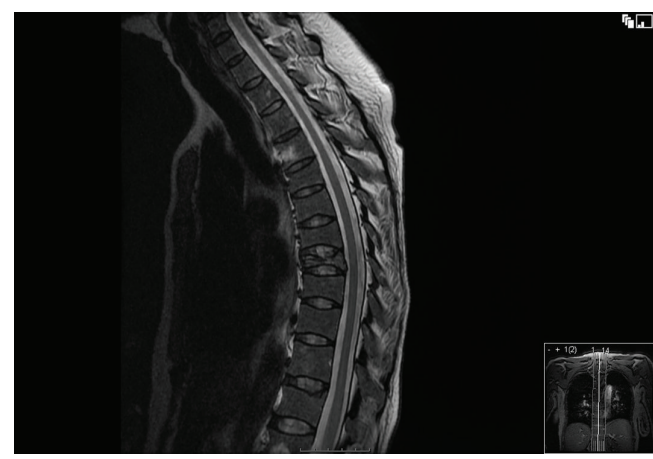

(a)

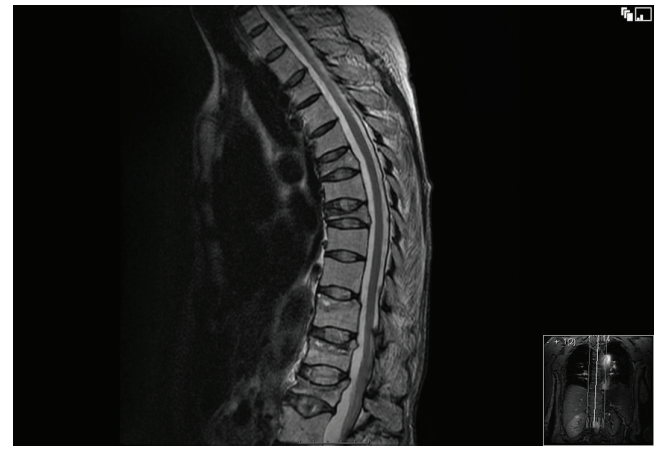

(c)

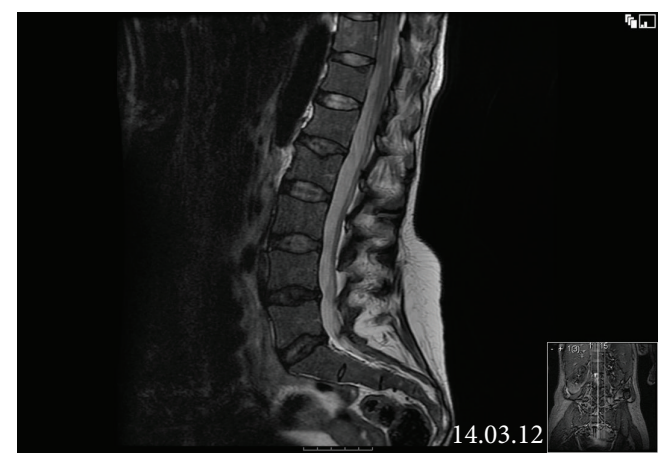

(b)

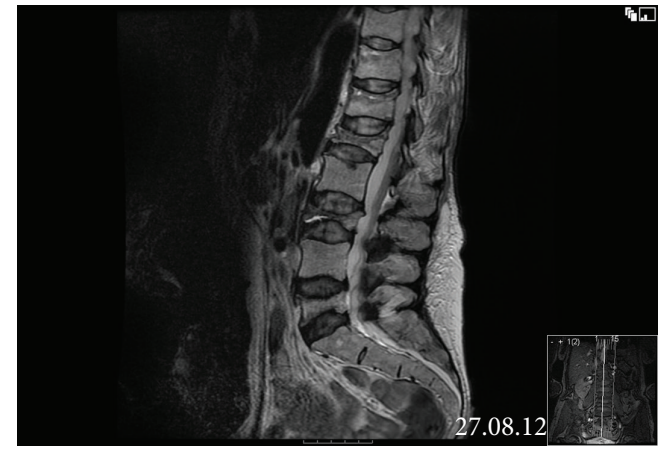

(d)

FiguRE 4: MRI spine. T2 fat-saturated axial view at the initial staging showed a compression fracture of T8 (a) and no other osseous lesions $(\mathrm{a}, \mathrm{b})$. Five months later, appearances were suspicious for lymphomatous infiltration with abnormal signal in T11 and T12 vertebral bodies and multilevel compression fractures of thoracic spine (c) and lumbar spine (d). 
Her previous use of hydroxyurea is unlikely to be associated with the current presentation. It was discontinued 18 years ago. The concerns regarding leukemogenicity were largely disproved in larger studies about the use of hydroxyurea in ET [41-43] and sickle cell disease [44]. We could not identify any reported cases of PBL in association with hydroxyurea.

In conclusion, we present a case of primary cutaneous $\mathrm{PBL}$ in the setting of longstanding pyrimethamine use for a myeloproliferative disorder. It is quite possible that the long-term pyrimethamine use resulted in a dysregulated immune system and the occurrence of PBL in this otherwise healthy 62 -year-old female. Age-related immunosenescence may have played a role.

\section{References}

[1] S. H. Swerdlow, E. Campo, N. L. Harris et al., WHO Classification of Tumours of Haematopoietic and Lymphoid Tissues Lyon, France: International Agency for Research on Cancer, 2008.

[2] H. J. Delecluse, I. Anagnostopoulos, F. Dallenbach et al., "Plasmablastic lymphomas of the oral cavity: a new entity associated with the human immunodeficiency virus infection," Blood, vol. 89, no. 4, pp. 1413-1420, 1997.

[3] J. J. Liu, L. Zhang, E. Ayala et al., "Human immunodeficiency virus (HIV)-negative plasmablastic lymphoma: a single institutional experience and literature review," Leukemia Research, vol. 35, no. 12, pp. 1571-1577, 2011.

[4] J. J. Castillo, E. S. Winer, D. Stachurski et al., "HIV-negative plasmablastic lymphoma: not in the mouth," Clinical Lymphoma Myeloma and Leukemia, vol. 11, no. 2, pp. 185-189, 2011.

[5] J. J. Castillo and J. L. Reagan, "Plasmablastic lymphoma: a systematic review," The Scientific World Journal, vol. 11, pp. 687696, 2011.

[6] C. L. Black, E. Foster-Smith, I. D. Lewis et al., "Post-transplant plasmablastic lymphoma of the skin," Australasian Journal of Dermatology, 2012.

[7] R. Maria, A. Manuel, M. Luisa et al., "Extensive cutaneous involvement by plasmablastic lymphoma," Journal of the American Academy of Dermatology, vol. 66, no. 4, supplement 1, p. AB137, 2012.

[8] M. Bibas, S. Grisetti, L. Alba, G. Picchi, F. Del Nonno, and A. Antinori, "Patient with HIV-associated plasmablastic lymphoma responding to bortezomib alone and in combination with dexamethasone, gemcitabine, oxaliplatin, cytarabine, and pegfilgrastim chemotherapy and lenalidomide alone," Journal of Clinical Oncology, vol. 28, no. 34, pp. e704-e708, 2010.

[9] M. Corti, L. D. Carolis, R. Solari et al., "Non Hodgkin's lymphoma with cutaneous involvement in AIDS patients: report of five cases and review of the literature," Brazilian Journal of Infectious Diseases, vol. 14, no. 1, pp. 81-85, 2010.

[10] D. Hansra, N. Montague, A. Stefanovic et al., "Oral and extraoral plasmablastic lymphoma: similarities and differences in clinicopathologic characteristics," American Journal of Clinical Pathology, vol. 134, no. 5, pp. 710-719, 2010.

[11] S. Apichai, A. Rogalska, I. Tzvetanov, Z. Asma, E. Benedetti, and S. Gaitonde, "Multifocal cutaneous and systemic plasmablastic lymphoma in an infant with combined living donor small bowel and liver transplant," Pediatric Transplantation, vol. 13, no. 5, pp. 628-631, 2009.
[12] P. Chabay, E. De Matteo, M. Lorenzetti et al., "Vulvar plasmablastic lymphoma in a HIV-positive child: a novel extraoral localisation," Journal of Clinical Pathology, vol. 62, no. 7, pp. 644-646, 2009.

[13] C. Hernandez, A. S. Cetner, and E. L. Wiley, "Cutaneous presentation of plasmablastic post-transplant lymphoproliferative disorder in a 14-month-old," Pediatric Dermatology, vol. 26, no. 6, pp. 713-716, 2009.

[14] A. Jambusaria, D. Shafer, H. Wu, T. Al-Saleem, and C. Perlis, "Cutaneous plasmablastic lymphoma," Journal of the American Academy of Dermatology, vol. 58, no. 4, pp. 676-678, 2008.

[15] J. Bernabeu-Wittel, D. H. Gonzalo, R. Luque, J. J. Borrero, and J. Conejo-Mir, "Cutaneous nodules as diagnostic key of an extraoral plasmablastic lymphoma in an human immunodeficiency virus-infected patient," Journal of the European Academy of Dermatology and Venereology, vol. 22, no. 1, pp. 127-129, 2008.

[16] V. Zaragoza, L. Martínez, A. Pérez-Ferriols, and V. Alegre, "Cutaneous presentation of plasmablastic lymphoma in a patient with HIV Infection," Actas Dermo-Sifiliográficas, vol. 99, no. 10, pp. 820-821, 2008.

[17] M. Redmond, J. Quinn, P. Murphy, S. Patchett, and M. Leader, "Plasmablastic lymphoma presenting as a paravertebral mass in a patient with Crohn's disease after immunosuppressive therapy," Journal of Clinical Pathology, vol. 60, no. 1, pp. 80-81, 2007.

[18] J. L. Arbiser, K. P. Mann, E. M. Losken et al., "Presence of p16 hypermethylation and Epstein-Barr virus infection in transplant-associated hematolymphoid neoplasm of the skin," Journal of the American Academy of Dermatology, vol. 55, no. 5, pp. 794-798, 2006.

[19] W. Liu, M. E. Lacouture, J. Jiang et al., "KSHV/HHV8-associated primary cutaneous plasmablastic lymphoma in a patient with Castleman's disease and Kaposi's sarcoma," Journal of Cutaneous Pathology, vol. 33, supplement 2, pp. 46-51, 2006.

[20] J. P. Dales, A. Harket, D. Bagnères et al., "Plasmablastic lymphoma in a patient with HIV infection: an unusual case located in the skin," Annales de Pathologie, vol. 25, no. 1, pp. 45-49, 2005.

[21] S. T. P. Deloose, L. A. Smit, F. T. Pals, M. J. Kersten, C. J. M. Noesel, and S. T. Pals, "High incidence of Kaposi sarcoma-associated herpesvirus infection in HIV-related solid immunoblastic/plasmablastic diffuse large B-cell lymphoma," Leukemia, vol. 19, no. 5, pp. 851-855, 2005.

[22] M. Gilaberte, F. Gallardo, B. Bellosillo et al., "Recurrent and self-healing cutaneous monoclonal plasmablastic infiltrates in a patient with AIDS and Kaposi sarcoma," British Journal of Dermatology, vol. 153, no. 4, pp. 828-832, 2005.

[23] L. B. Jordan, A. M. Lessells, and J. R. Goodlad, "Plasmablastic lymphoma arising at a cutaneous site," Histopathology, vol. 46, no. 1, pp. 113-115, 2005.

[24] S. Verma, G. E. Frambach, K. H. Seilstad, G. Nuovo, P. Porcu, and C. M. Magro, "Epstein-Barr virus-associated B-cell lymphoma in the setting of iatrogenic immune dysregulation presenting initially in the skin," Journal of Cutaneous Pathology, vol. 32, no. 7, pp. 474-483, 2005.

[25] S. Verma, G. J. Nuovo, P. Porcu, R. A. Baiocchi, A. N. Crowson, and C. M. Magro, "Epstein-Barr virus- and human herpesvirus 8 -associated primary cutaneous plasmablastic lymphoma in the setting of renal transplantation," Journal of Cutaneous Pathology, vol. 32, no. 1, pp. 35-39, 2005. 
[26] L. Colomo, F. Loong, S. Rives et al., "Diffuse large B-cell lymphomas with plasmablastic differentiation represent a heterogeneous group of disease entities," American Journal of Surgical Pathology, vol. 28, no. 6, pp. 736-747, 2004.

[27] M. M. Hanasono, B. M. Parrett, and A. S. Breitbart, "Posttransplant lymphoproliferative disorder presenting as a cutaneous forehead mass," Otolaryngology, vol. 130, no. 3, pp. 372-374, 2004.

[28] P. Häusermann, N. Khanna, M. Buess et al., "Cutaneous plasmablastic lymphoma in an HIV-positive male: an unrecognized cutaneous manifestation," Dermatology, vol. 208, no. 3, pp. 287290, 2004.

[29] N. J. Samolitis, J. S. Bharadwaj, J. R. Weis, and R. M. Harris, "Post-transplant lymphoproliferative disorder limited to the skin," Journal of Cutaneous Pathology, vol. 31, no. 6, pp. 453-457, 2004.

[30] J. Teruya-Feldstein, E. Chiao, D. A. Filippa et al., "CD20negative large-cell lymphoma with plasmablastic features: a clinically heterogenous spectrum in both HIV-positive and negative patients," Annals of Oncology, vol. 15, no. 11, pp. 16731679, 2004.

[31] I. Nicol, T. Boye, F. Carsuzaa et al., "Post-transplant plasmablastic lymphoma of the skin," British Journal of Dermatology, vol. 149, no. 4, pp. 889-891, 2003.

[32] F. Liu, N. Asano, A. Tatematsu et al., "Plasmablastic lymphoma of the elderly: a clinicopathological comparison with agerelated Epstein-Barr virus-associated B cell lymphoproliferative disorder," Histopathology, vol. 61, no. 6, pp. 1183-1197, 2012.

[33] A. Jafarzadeh, Z. M. Hassan, M. Ebtekar, S. Mohaghegh-Hazrati, and T. Tiraihi, "Time-dependent changes of immunologic responses after burn injury and immunomodulation by cimetidine and pyrimethamine in an animal model," Pakistan Journal of Pharmaceutical Sciences, vol. 23, no. 4, pp. 367-373, 2010.

[34] M. Ebtekar and Z. M. Hassan, "Effect of immunomodulators pyrimethamine and cimetidine on immunosuppression induced by sulfur mustard in mice," International Journal of Immunopharmacology, vol. 15, no. 4, pp. 533-541, 1993.

[35] A. Takakura, E. A. Nelson, N. Haque et al., "Pyrimethamine inhibits adult polycystic kidney disease by modulating STAT signaling pathways," Human Molecular Genetics, vol. 20, no. 21, pp. 4143-4154, 2011.

[36] A. M. Giammarioli, A. Maselli, A. Casagrande et al., "Pyrimethamine induces apoptosis of melanoma cells via a caspase and cathepsin double-edged mechanism," Cancer Research, vol. 68, no. 13, pp. 5291-5300, 2008.

[37] M. R. Khorramizadeh, F. Saadat, F. Vaezzadeh et al., "Suppression of telomerase activity by pyrimethamine: implication to cancer," Iranian Biomedical Journal, vol. 11, no. 4, pp. 223-228, 2007.

[38] F. Saadat, M. R. Khorramizadeh, and A. Mirshafiey, "Chemoprevention by pyrimethamine," Immunopharmacology and Immunotoxicology, vol. 27, no. 2, pp. 233-240, 2005.

[39] S. J. Bowcock, D. C. Linch, S. J. Machin, and J. W. Stewart, "Pyrimethamine in the myeloproliferative disorders: a forgotten treatment?" Clinical and Laboratory Haematology, vol. 9, no. 2, pp. 129-136, 1987.

[40] J. M. Costello and D. M. Becroft, "Drug reaction simulating malignant lymphoma: a case due to pyrimethamine," New Zealand Medical Journal, vol. 86, no. 599, pp. 430-432, 1977.

[41] F. Passamonti, E. Rumi, E. Pungolino et al., "Life expectancy and prognostic factors for survival in patients with polycythemia vera and essential thrombocythemia," American Journal of Medicine, vol. 117, no. 10, pp. 755-761, 2004.

[42] S. Cortelazzo, G. Finazzi, M. Ruggeri et al., "Hydroxyurea for patients with essential thrombocythemia and a high risk of thrombosis," The New England Journal of Medicine, vol. 332, no. 17, pp. 1132-1136, 1995.

[43] C. N. Harrison, P. J. Campbell, G. Buck et al., "Hydroxyurea compared with anagrelide in high-risk essential thrombocythemia," The New England Journal of Medicine, vol. 353, no. 1, pp. 33-45, 2005.

[44] M. H. Steinberg, W. F. McCarthy, O. Castro et al., "The risks and benefits of long-term use of hydroxyurea in sickle cell anemia: a 17.5 year follow-up," American Journal of Hematology, vol. 85, no. 6, pp. 403-408, 2010. 


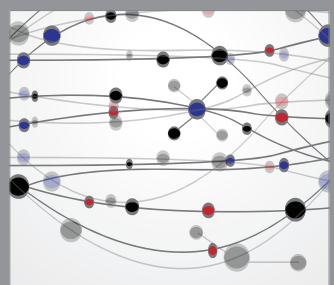

The Scientific World Journal
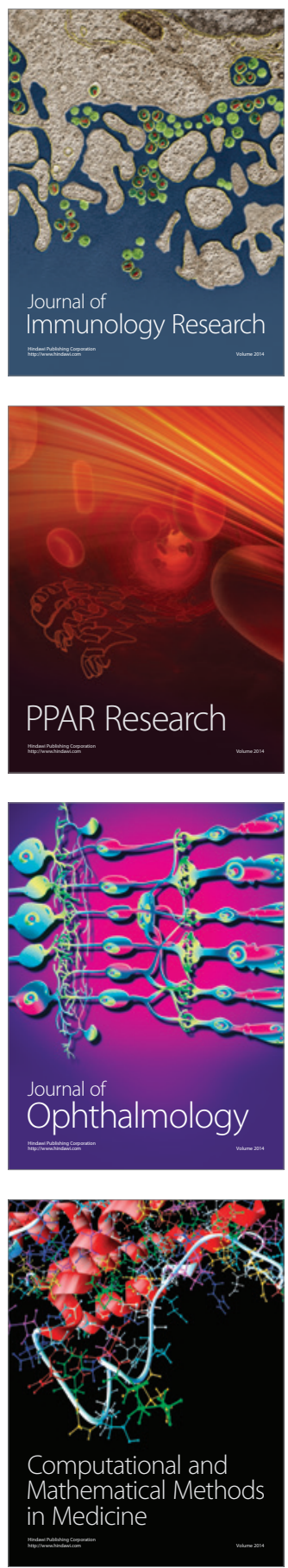

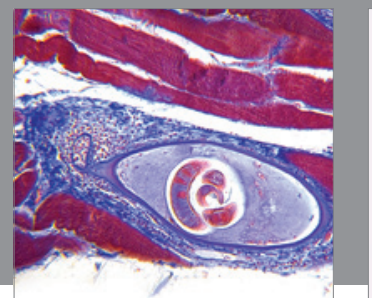

Gastroenterology

Research and Practice
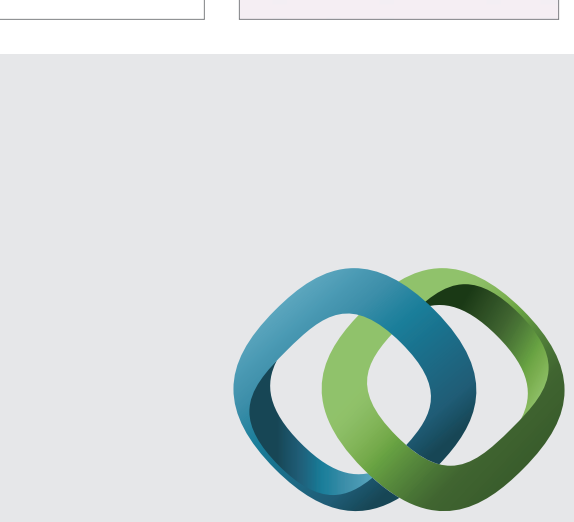

\section{Hindawi}

Submit your manuscripts at

http://www.hindawi.com
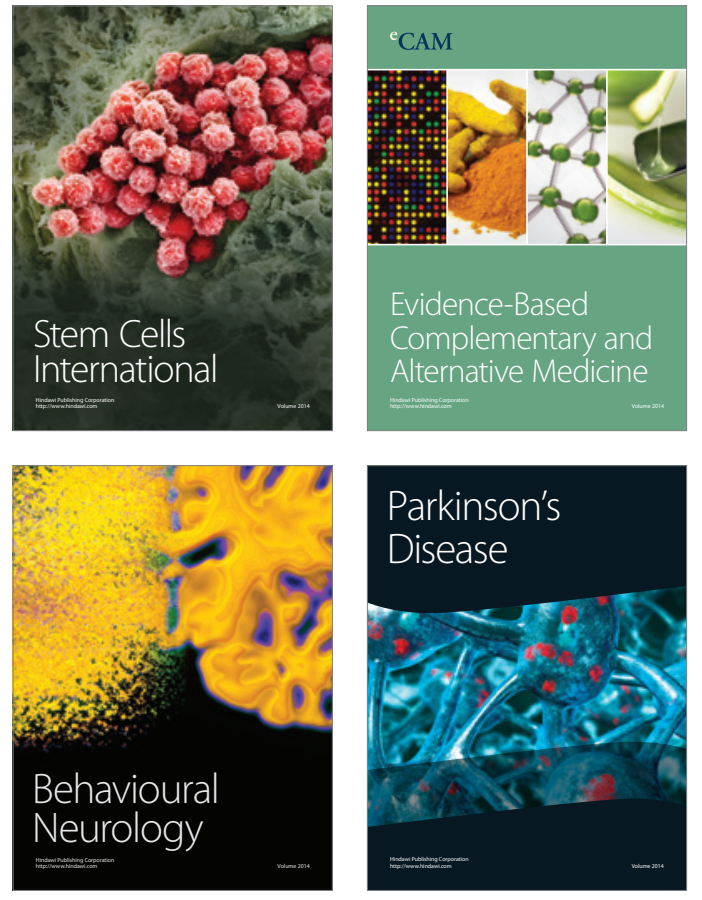
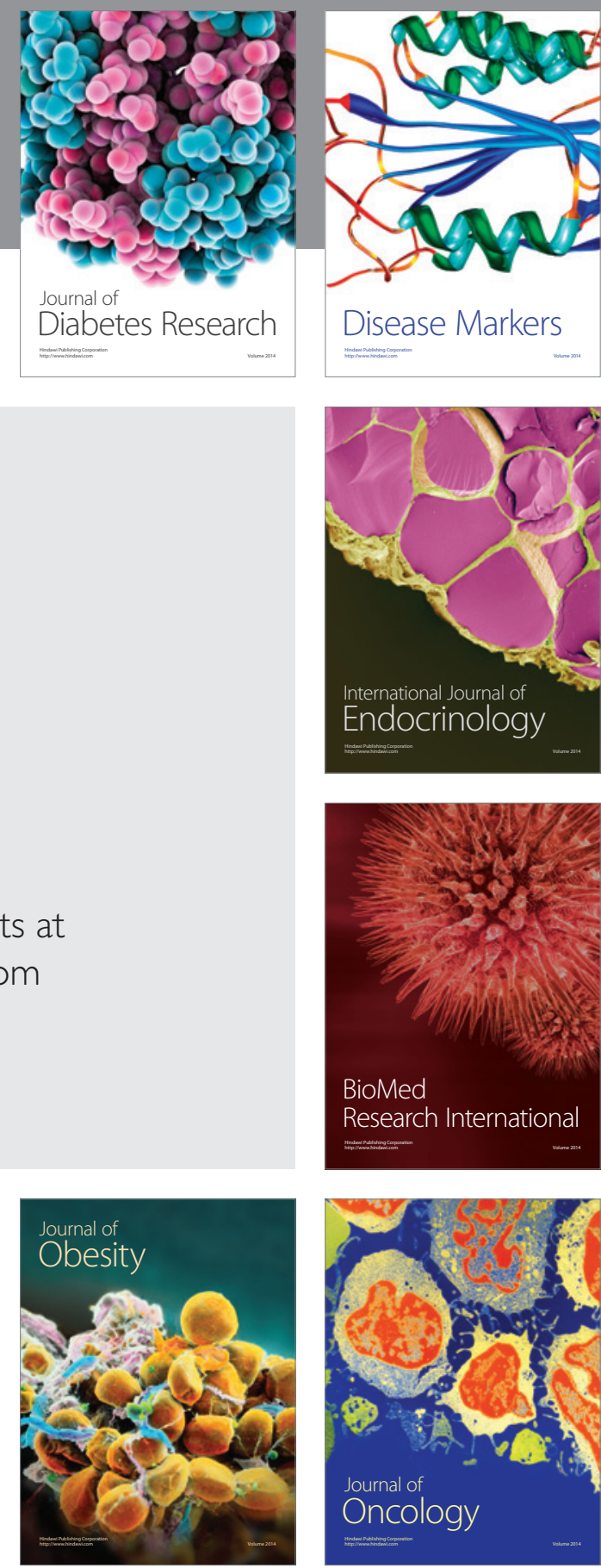

Disease Markers
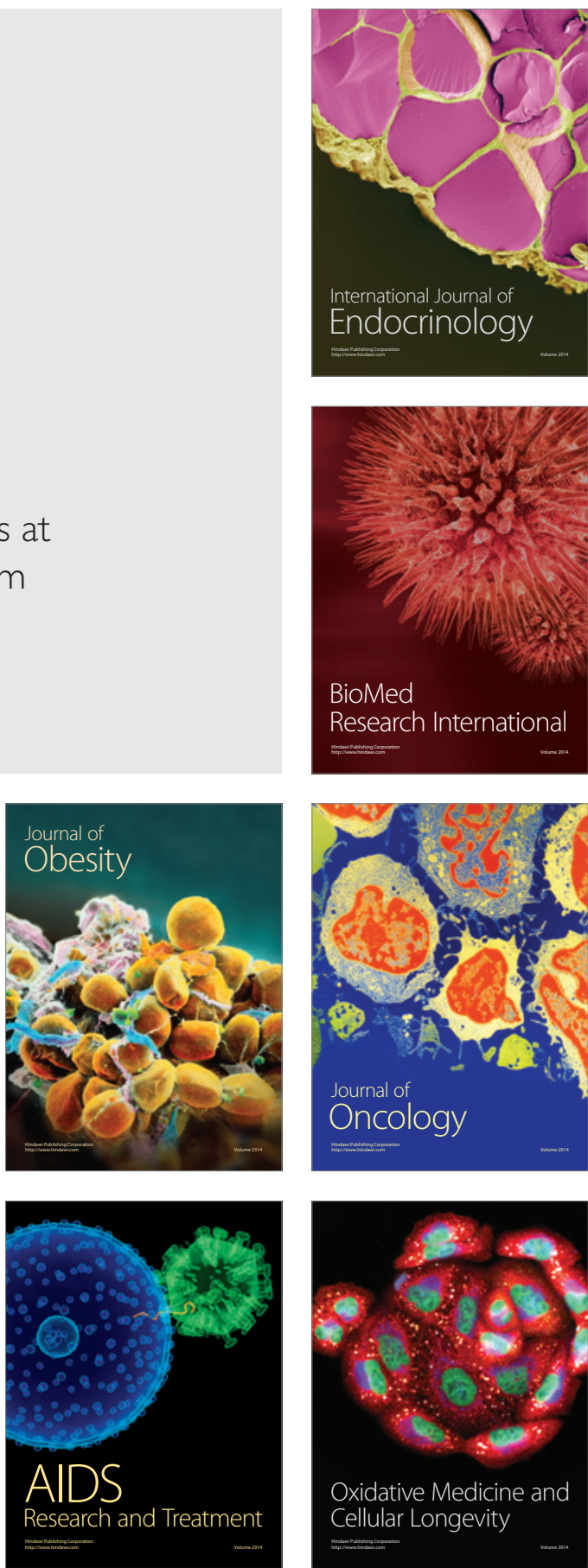